SAMMLUNG TUSCULUM

Wissenschaftliche Beratung:

Gerhard Fink, Manfred Fuhrmann,

Erik Hornung, Joachim Latacz, Rainer Nickel 

PETRONIUS

\section{SAT YRICA}

Schelmenszenen

Lateinisch - deutsch von Konrad Müller und Wilhelm Ehlers

Mit einer Bibliographic von Niklas Holzberg

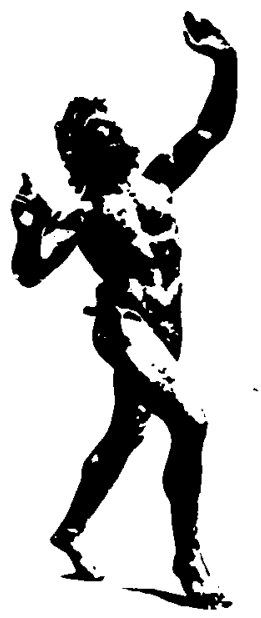

ARTEMIS \& WINKLER 
Tanzender Satyr, späthellenistische Bronzestatuette aus Pomperi

(Neapel, Museo Nazionale). Foto: Museum für Abgüsse

klassischer Bildwerke, München

Bibliographische Information der Deutschen Bibliochek

Die Deutsche Bibliothek verzeichnet diese Publikation in der Deutschen Nationalbibliothek; detaillierte bibliographische Daten sind im Internet über http://dnb.ddb.de abrufbar.

5. Auflage 2004

(C) $20_{4}$ Parmos Verlag GmbH \& Co. KG

Artemis \& Winkler Verlag, Düsseldorf/Zürich

C 1983 Artemis Verlags-AG Zürich

Alle Rechte vorbehalten.

Druck und Verarbeitung: Pustet, Regensburg

ISBN 3-7608-1572-3

www.patmos.de 


\section{HEINZ HAFFTER}

zum 1. 6. 1983 